\title{
Poor academic performance among adolescents with epilepsy in Kaduna, Northern Nigeria: A case-control study
}

\author{
FT Nuhu, A J Yusuf, T L Sheikh, E E Eseigbe \\ Federal Neuropsychiatric Hospital, Kaduna, Nigeria \\ FT Nuhu, MB BS, MNIM, FMCPsych \\ T L Sheikh, MB BS, MSc, FWACP \\ Department of Psychiatry, Abmadu Bello University Teaching Hospital, Zaria, Nigeria \\ A J Yusuf, MB BS, FWACP, FMCPsych \\ Department of Paediatrics, Ahmadu Bello University Teaching Hospital, Zaria, Nigeria \\ E E Eseigbe, MB BS, MNIM, FWACP
}

Corresponding author: F T Nubu (funshonubu@yahoo.com)

\begin{abstract}
Background. Adolescents with epilepsy experience significant academic difficulties. However, little is known about the effects of epilepsy on the academic performance of adolescents with the disorder in Northern Nigeria.

Objective. To assess the academic performance of adolescents with epilepsy and factors associated with poor performance in this population in a Northern Nigerian setting.

Methods. The socio-demographic/clinical characteristics of 77 consecutive adolescents (aged 12 - 17 years) with epilepsy attending the Child and Adolescent Clinic of Federal Neuropsychiatric Hospital, Kaduna, North-West, between March 2008 and September 2010 and the socio-demographic characteristics of 76 controls (matched for age and sex) were recorded. Information concerning school attendance and academic performance of the subjects and the controls were obtained from the adolescents and their parents or caregivers.

Results. The mean ages of the subjects and the controls were 15.1 (standard deviation (SD) 2.1) and 14.7 (SD 1.7) years, respectively $(p>0.05)$, the mean duration of illness was 6.1 (SD 4.6) years, the mean seizure-free period was 16.8 (SD 15.6) weeks, and 64.9\% of the subjects and $57.9 \%$ of the controls were males. Forty-six subjects (59.7\%) and 12 controls (15.8\%) had poor academic performance $(p<0.001)$. Long duration of illness, short seizure-free periods and irregular school attendance were significantly associated with poor academic performance $(p<0.05)$.

Conclusions. Poor academic performance is common among adolescents with epilepsy and is associated with early onset, poor seizure control and missing school. Efforts should be made to control seizures and educate society about the illness.
\end{abstract}

S Afr J CH 2012;6(4):132-134. DOI:10.7196/SAJCH.512

Epilepsy is the most common severe non-infectious neurological disorder affecting both children and adults, ${ }^{1}$ and the majority of sufferers live in developing countries. ${ }^{2}$ In children and adolescents epilepsy is associated with impairment in academic performance, ${ }^{3-7}$ which may limit future employment opportunities. ${ }^{8}$

In Nigeria, studies have linked epilepsy with missing school, dropping out of school and poor academic performance. ${ }^{4,11}$ Factors that predispose a child or adolescent with epilepsy to poor school performance include the age of the child, age of onset of seizures, seizure frequency, ${ }^{12}$ type of seizure, IQ of the child, ${ }^{4}$ poor memory, inattention, ${ }^{13}$ low self-esteem, and psychosocial and sociodemographic factors. ${ }^{9}$

The aims and objectives of this study were therefore to assess the academic performance of adolescents with epilepsy in Kaduna and identify factors that may be associated with poor performance in this population in a Northern Nigerian setting.

\section{Methods}

The study was carried out in the outpatient clinic of Federal Neuropsychiatric Hospital, Kaduna, North-West, Nigeria. The hospital is a tertiary health institution that receives referrals (mostly psychiatric, but also neurological) from virtually all the states in Northern Nigeria and the Federal Capital Territory Abuja. In this cross-sectional study, the socio-demographic/clinical characteristics of 77 consecutive adolescents (aged $12-17$ years) with epilepsy attending the Child and Adolescent Clinic of the hospital between March 2008 and September 2010 and the socio-demographic characteristics of 76 controls (matched for age and sex) were recorded. Information concerning school attendance (regularity of attendance at school) and academic performance (academic records for the three most recent consecutive terms) of the patients and the controls were obtained from the adolescents and their parents or caregivers. For the purposes of the study, poor academic performance was defined as persistent below-average performance as reported by the informants, or a decline from previous performance since the onset of the illness 
or in the three terms before evaluation. For the patients, seizure frequency and the seizure-free period (calculated from the day of last seizure to the day of interview), duration of illness, age at onset, type of seizure, and types of medication were obtained from the case files. We excluded patients with co-morbid psychiatric disorders, cerebral palsy, sensory impairment or speech disorders.

The diagnosis of epilepsy was based clinically on information from eye-witness accounts of two or more unprovoked generalised seizure episodes. Some subjects were diagnosed on the basis of the clinical history and abnormalities found on electro-encephalography (EEG). EEG is a useful tool in diagnosing epilepsy, but some patients with epilepsy do not manifest EEG abnormalities, while some normal subjects show nonspecific EEG findings. ${ }^{14}$

The Research and Ethics Committee of Federal Neuropsychiatric Hospital gave approval for the study. Informed consent was obtained from parents/caregivers of the subjects, and the aims and objectives were explained to the subjects.

\section{Statistical analysis}

We analysed the data using the 15th edition of the Statistical Package for Social Sciences (SPSS-15) 15 by calculating frequencies, means and standard deviations (SD). Associations between variables and academic performance were determined by cross-tabulation, using the chi-square test for calculation and setting the level of significance at $p<0$.

\section{Results}

The mean ages of the patients and the controls were 15.1 (SD 2.1) and 14.7 (SD 1.7) years, respectively $(p>0.05) ; 64.9 \%$ of the patients and $57.9 \%$ of the controls were males. For the patients, the mean duration of illness was 6.1 (SD 4.6) years and the mean seizurefree period 16.8 (SD 15.6) weeks. Further socio-demographic characteristics of the patients are set out in Table 1.

Forty-six patients (59.7\%) and 12 controls (15.8\%) had poor academic performance $(p<0.001)$. Long duration of illness, short seizure-free periods and irregular school attendance were significantly associated with poor performance $(p<0.05)$ (Table 2$)$. Other sociodemographic/clinical variables were not significantly associated with poor performance $(p>0.05)$.

\section{Discussion}

More than half of the patients had poor academic performance over the three terms before evaluation. This figure is relatively high and is in keeping with some previous reports. ${ }^{10,16}$ Other studies have reported a lower prevalence. ${ }^{3,11}$ However, some studies have investigated children and adolescents with mental retardation and so could have missed milder declines in school performance.

About $57 \%$ of the subjects reported that they missed school frequently because of their illness. Some stayed at home to avoid being mocked by schoolmates should they have a seizure at school, while others had frequent seizures that prevented them from going to school regularly. In addition, some of them had stopped going to school, either on the advice of their teachers or the school authority, or because of a parental decision; $18.2 \%$ of the subjects had in fact been expelled from school because of recurrent seizures. Knowledge about epilepsy is still poor, ${ }^{17,18}$ and this could be responsible for the attitudes of the teachers, school authorities and parents.

We found long duration of illness (and therefore possibly an early age of onset), short seizure-free periods (which may indicate poor seizure control) and missing school to be significant factors associated with poor academic performance. This is similar to findings from some previous studies. ${ }^{10-12}$ Poor performance may be the cumulative effect of seizures over the years, which may cause direct brain damage with resultant cognitive deficits. In addition, an adolescent who has frequent seizures is more likely to be mocked, to miss school or even to be expelled by the school authority. Each of these factors may act alone or in combination to produce a synergistic negative effect on the academic performance of the affected individual.

\section{Limitations}

This was a hospital-based cross-sectional study in which a standardised instrument was not used. In addition, some psychosocial factors such as effects of stigma and subjects' self-esteem were not assessed.

\section{Conclusion}

Despite the above limitations, the results of this study show that adolescents with epilepsy have significantly impaired academic performance, those with a long duration of illness and short seizure-free periods and who miss school frequently being at particular risk. Table 1. Some socio-demographic/clinical characteristics
of the patients

\begin{tabular}{|c|c|c|}
\hline Variables & Frequency $(n)$ & $\%$ \\
\hline \multicolumn{3}{|l|}{ Gender } \\
\hline Male & 50 & 64.9 \\
\hline Female & 27 & 35.1 \\
\hline \multicolumn{3}{|l|}{ Education } \\
\hline Primary & 35 & 45.5 \\
\hline Secondary & 33 & 42.9 \\
\hline Islamiya* & 9 & 11.7 \\
\hline \multicolumn{3}{|l|}{ Living with } \\
\hline Parents & 67 & 87.0 \\
\hline Other relatives & 10 & 13.0 \\
\hline \multicolumn{3}{|l|}{ Type of seizure } \\
\hline General & 60 & 77.9 \\
\hline Partial & 17 & 22.1 \\
\hline \multicolumn{3}{|c|}{ Family history of epilepsy } \\
\hline Yes & 27 & 35.1 \\
\hline No & 50 & 64.9 \\
\hline \multicolumn{3}{|l|}{ Drugs } \\
\hline Carbamazepine & 66 & 85.7 \\
\hline Sodium valproate & 9 & 11.7 \\
\hline Combination & 2 & 2.6 \\
\hline \multicolumn{3}{|l|}{ School attendance } \\
\hline Regular & 33 & 42.9 \\
\hline Not regular & 44 & 57.1 \\
\hline \multicolumn{3}{|c|}{ Expulsion from school } \\
\hline Yes & 14 & 18.2 \\
\hline No & 63 & 81.8 \\
\hline \multicolumn{3}{|c|}{ Academic performance } \\
\hline Impaired & 41 & 53.2 \\
\hline Not impaired & 36 & 46.8 \\
\hline
\end{tabular}


Table 2. Academic performance and some socio-demographic and clinical variables

\begin{tabular}{|c|c|c|c|c|c|}
\hline Variables & Good performance, $n(\%)$ & Impaired performance, $n(\%)$ & $\chi^{2}$ & df & $p$-value \\
\hline \multicolumn{6}{|l|}{ Illness duration } \\
\hline $1-5$ years & $22(59.5)$ & $15(40.5)$ & 11.464 & 2 & 0.003 \\
\hline $6-10$ years & $5(18.5)$ & $22(81.5)$ & & & \\
\hline$>10$ years & $4(30.8)$ & $9(69.2)$ & & & \\
\hline \multicolumn{6}{|l|}{ Seizure free } \\
\hline$<6$ months & $15(24.6)$ & $46(75.4)$ & 29.969 & 2 & $<0.001$ \\
\hline 6 months - 1 year & $10(100.0)$ & - & & & \\
\hline$>1$ year & $6(100.0)$ & - & & & \\
\hline \multicolumn{6}{|l|}{ School attendance } \\
\hline Regular & $25(75.8)$ & $8(24.2)$ & 19.515 & 1 & $<0.001$ \\
\hline Irregular & $6(13.6)$ & $38(86.4)$ & & & \\
\hline
\end{tabular}

All adolescents with epilepsy should therefore be closely monitored with a view to achieving good seizure control. In addition, parents, teachers and the general public should be educated about epilepsy.

\section{of the subjects, $18.2 \%$ \\ 负目势 had been expelled 32 \\ from school because of \\ recurrent seizures.}

\section{References}

1. European Declaration on Epilepsy, Heidelberg, Germany. 25 October 1998. http://onlinelibrary.wiley.com/doi/10.1046/j.1528-1157.43.s6.4.x/pdf (accessed 6 November 2012).

2. Jallon P. Epilepsy in developing countries. Epilepsia 1997;38:1143-1151. [http://dx.doi.org/10.111/j.1528-1157.1977.tb01205.x]

3. Ibekwe RC, Ojinnaka NC, Iloeje SO. Factors influencing the academic performance of school children with epilepsy. J Trop Paed 2007;53(5):338343. [http://dx.doi.org/10.1093/tropej/fmm034]

4. Lagunju IA, Akinyinka O, Orimadegun A, et al. Health-related quality of life of Nigerian children with epilepsy. African Journal of Neurological Sciences 2009;8(1).

5. Aldenkamp AP. Learning disabilities in children with epilepsy In: Aldenkamp AP, Alpharts WCJ, Meinard H, Stokes G, eds. Education and Epilepsy: Proceedings of an International Workshop on Education and Epilepsy. Berwyn, PA: Swets North America, 1987:21-37.

6. Smith ML,Elliott IM,Lach L. Cognitive skills in children with intractable epilepsy: Comparison of surgical and non-surgical candidates. Epilepsia 2002;43:631-637.

7. Williams J. Learning and behavior in children with epilepsy. Epilepsy Behav 2003;4(2):107-111. [http://dx.doi.org/10.1016/S1525-5050(03)00024-6]

8. Macleods JS, Austin JK. Stigma in the lives of adolescents with epilepsy: A review of literature. Epilepsy Behav 2003;4(2):112-117. [http://dx.doi.org/10.1016/ S1525-5050(03)0007-6]

9. Adewuya AO, Oseni SBA, Okeniyi JAO. School performance of Nigerian adolescents with epilepsy. Epilepsia 2006;47(2):415-420,

10. Iloeje SO. The pattern of childhood epilepsy with mental retardation in Nigeria.J Trop Pediatr 1989;35(4):163-168.

11. Sunmonu TA, Komolafe MA, Ogunrin AO, Oladimeji BY, Ogunniyi A. Intellectual impairment in patients with epilepsy in Ile-Ife, Nigeria. Acta Neurol Scand 2008;118(6):395-401. [http://dx.doi.org/10.1111/j.16000404.2008.01054.x]

12. Seindenberg M, Beck N, Geisser M, et al. Academic achievement of children with epilepsy. Epilepsia 1986;27(6):753-759.

13. Williams J, Phillips T, Griebel ML, et al. Factors associated with academic achievement in children with controlled epilepsy. Epilepsy Behav 2001;2(3):217223. [http://dx.doi.org/10.1006/ebeh.2001.0166]

14. Osuntokun BO, Odeku EL. Epilepsy in Ibadan, Nigeria: a study of 522 cases. Afr J Med Med Sci 1970;1:185-200.

15. Statistical Package for Social Sciences, Version 15 (SPSS-15). Chicago: SPSS Inc., 2006.

16. Sturniolo MG, Galletti F. Idiopathic epilepsy and school achievement. Arch Disease Child 1994;70:424-428. [http://dx.doi.org/10.1136/adc.70.5.424]

17. Ojinnaka NC. Teachers' perception of epilepsy in Nigeria: A community based study. Seizure 2002;11:386-391.

18. Sanya EO, Salami TAT, Goodman OO, Buhari OIN, Araoye MO. Perception and attitude to epilepsy among teachers in primary, secondary and tertiary educational institutions in middle-belt, Nigeria. Trop Doct 2005;35:153-156. [http://dx.doi.org/10.1258/0049475054620905] 